Результаты работы сосудистых центров и образовательных мероприятий по вторичной профилактике инсультов в Тюменской области

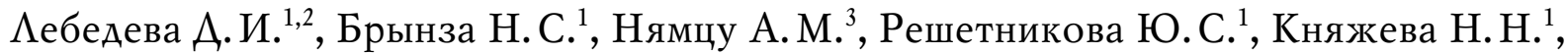 \\ Акарачкова Е.С. ${ }^{4}$, Орлова А.С. \\ ${ }^{1}$ ФББОУ ВО “Тюменский государственный медицинский университет” Министерства здравоохранения \\ Российской Федерации. Тюмень; ${ }^{2}$ ГАУЗ ТО “Областной лечебно-реабилитационный центр”. Тюмень; \\ ${ }^{3}$ ГАУ ТО “Медицинский информационно-аналитический центр”. Тюмень; ${ }^{4}$ Международное общество

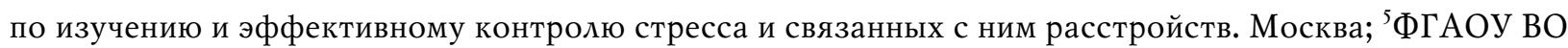 \\ “Первый Московский государственный университет им. И.М. Сеченова Министерства здравоохранения \\ Российской Федерации (Сеченовский университет)”. Москва, Россия
}

Цель. Оценить основные результаты работы сосудистых центров и отделений Тюменской области, а также образовательных мероприятий по вторичной профилактике инсульта за период 2011-2017гг. Материал и методы. Эффективность работы сосудистых центров и отделений Тюменской области проведена по стандартным показателям: время госпитализации, соблюдение правил маршрутизации, своевременное выполнение диагностических мероприятий, частота проведения и эффективность тромболитической терапии. Результаты работы школ, организованных для пациентов с инсультом и их родственников, изучали с помощью анкетирования, которое проводится после завершения каждой образовательной программы.

Результаты. Продемонстрировано улучшение основных показателей работы сосудистых центров и отделений, большинство из которых достигли целевых показателей по РФ. Отмечена высокая посещаемость образовательных мероприятий по вторичной профилактике инсульта (8254 человека за оцениваемый период). Проанализированы 2200 анкет слушателей, которые показали удовлетворенность респондентов результатами проведенных школ, а также качеством и организацией занятий.
Заключение. Организация специализированной помощи больным с острым нарушением мозгового кровообращения в Тюменской области позволила увеличить число выполнений системной тромболитической терапии, снизить показатели летальности у пациентов с ишемическим инсультом и улучшить функциональные исходы. Проведение образовательных мероприятий для пациентов с инсультом и их родственников существенно повысило информированность целевой группы населения.

Ключевые слова: инсульт, сосудистый центр, вторичная профилактика, информированность пациентов, Тюменская область.

\section{Конфликт интересов: не заявлен.}

Кардиоваскулярная терапия и профилактика. 2019;18(1):107-112 http://dx.doi.org/10.15829/1728-8800-2019-1-107-112

Поступила 25/02-2018

Принята к публикации 06/07-2018

Рецензия получена 10/04-2018 (cc) BY 4.0

\title{
The results of implementation of specialized stroke units and educational programs aimed at the secondary
} prevention of stroke in Tyumen district

Lebedeva D.I. ${ }^{1,2}$, Brynza N. S. ${ }^{1}$, Nyamtsu A. M. ${ }^{3}$, Reshetnikova Yu. S. ${ }^{1}$, Kniazheva N. N. ${ }^{1}$, Akarachkova E. S. ${ }^{4}$, Orlova A. S. ${ }^{5}$

${ }^{1}$ Tyumen State Medical University. Tyumen; ${ }^{2}$ Regional Medical and Rehabilitation Center. Tyumen; ${ }^{3}$ Medical research and information center. Tyumen; ${ }^{4}$ International society of stress "Stress under control". Moscow; ${ }^{5}$ I. M. Sechenov First Moscow State Medical University. Moscow, Russia

Aim. To evaluate the main results of work of specialized stroke units and departments and implementation of educational campaigns on secondary stroke prevention in Tyumen district in 2011-2017.

Material and methods. Work efficacy of specialized stroke units and departments in Tyumen district was evaluated according to standard measures (length of hospital stay, compliance with patient routing rules, timely diagnostic measures, frequency and efficacy of thrombolysis). The results of work of schools for stroke patients and their caregivers were evaluated using questionnaires distributed after the end of each educational program.
Results. We demonstrated an improvement of main efficacy measures of stroke units and departments, with most of them reaching target values for Russian Federation. There was a high attendance of educational programs on secondary stroke prevention (8254 persons during the study period). A total of 2200 distributed questionnaires demonstrated a high level of satisfaction with the results of educational programs and the quality of education organization.

Conclusion. Implementation of specialized stroke units in Tyumen district enabled an increase of the number of patients receiving systemic thrombolytic therapy, a decrease of mortality and an improvement of

[Лебедева Д.И. - ${ }^{1}$ К.м.н., доцент кафедры профилактической и восстановительной медицины института HПР, ${ }^{2}$ главный врач, ORCID: 0000-0003-2478-9619, Брынза H. С. - д.м.н., доцент, зав. кафедрой общественного здоровья и здравоохранения, ORCID: 0000-0001-5985-1780, Нямцу А. М. - заместитель директора, ORCID: 0000-0003-4526-968X, Решетникова Ю. С. - к. М.Н., ассистент кафедры общественного здоровья и здравоохранения, ORCID: 0000-0001-6726-7103, Княжева H. Н. - к. М.н., доцент кафедры общественного здоровья и здравоохранения, ОRCID: 0000-0002-3139-5258, Акарачкова Е. С.* - д.м.н., президент международного общества "Стресс под контролем", ОRCID: 0000-0002-7629-3773, Орлова А.С. - к.м.н., доцент кафедры патологии человека лечебного факультета, ORCID: 0000-0001-9725-7491]. 
functional outcomes. Educational programs for stroke patients and their relatives increased the level of stroke awareness in the target population. Key words: stroke, stroke unit, secondary prevention, patients awareness, the Tyumen Region.

Conflicts of Interest: nothing to declare.

Cardiovascular Therapy and Prevention. 2019;18(1):107-112 http://dx.doi.org/10.15829/1728-8800-2019-1-107-112
Lebedeva D. I. ORCID: 0000-0003-2478-9619, Brynza N. S. ORCID: 0000-0001-5985-1780, Nyamtsu A.M. ORCID: 0000-0003-4526-968X, Reshetnikova Yu. S. ORCID: 0000-0001-6726-7103, Kniazheva N.N. ORCID: 0000-0002-3139-5258, Akarachkova E. S. ORCID: 0000-00027629-3773, Orlova A. S. ORCID: 0000-0001-9725-7491.

Received: 25/02-2018 Revision Received: 10/04-2018 Accepted: 06/07-2018

ГИ - геморрагический инсульт, ДИ - доверительный интервал, ИИ - ишемический инсульт, ОНМК - острое нарушение мозгового кровообращения, ОШ - отношение шансов, ПсО - первичное сосудистое отделение, РСЦ - региональный сосудистый центр, ТЛТ - тромболитическая терапия.

\section{Введение}

По оценкам в 2015г 17,9 млн человек во всем мире умерли от сердечно-сосудистых заболеваний, из них 6,3 млн - в результате острого нарушения мозгового кровообращения (ОНМК) [1]. За последние два десятилетия отмечается снижение стандартизированной по возрасту смертности от инсульта на $30 \%$ во всем мире [2]. В то же время абсолютные показатели ежегодного числа лиц, перенесших инсульт, увеличиваются. Это связано не только с общим старением популяции, но и со снижением смертности в результате инсульта [3, 4].

За последние несколько десятилетий достигнуто значительное улучшение в плане профилактики, лечения и реабилитации пациентов с инсультом $[5,6]$. В результате, наблюдается смещение акцента клинических рекомендаций с пассивного мониторинга показателей у пациентов с ОНМК в сторону активных ранних вмешательств, которые позволяют улучшить функциональный исход и выживаемость. К такого рода вмешательствам относят госпитализацию в специализированные сосудистые отделения оказания интенсивной медицинской помощи мультидисциплинарными бригадами [7], тромболизис [8], раннее нейрохирургическое вмешательство [9], а также раннюю реабилитацию [10].

Для эффективного лечения и достижения оптимальных результатов создаются специализированные сосудистые отделения, являющиеся ключевым компонентом стационарного лечения пациентов с инсультом, которые позволяют обеспечить своевременную диагностику, лечение, мониторинг основных показателей, профилактику и лечение осложнений, а также уменьшение сроков стационарного лечения [11].

В ходе проведенного в 2013г Кохрановского обзора, включавшего 21 клиническое исследование и 3994 участника, сравнивали эффективность лечения, проводимого в специализированном сосудистом отделении и в обычном неврологическом отделении. В специализированном сосудистом отделении продемонстрирована более низкая вероятность смертности в течение года $-18 \%$ по сравнению с 23\% в обычном неврологическом отделении; отно- шение шансов (ОШ) 0,81, 95\% доверительный интервал (ДИ) 0,69-0,94; снижение вероятности смерти или необходимости в постоянном уходе $35 \%$ в специализированном сосудистом отделении по сравнению с $40 \%$ в общем неврологическом отделении; ОШ 0,78, 95\% ДИ 0,68-0,89. Указанные улучшения не сопровождались увеличением продолжительности стационарного лечения [7]. Таким образом, внедрение специализированных сосудистых отделений для лечения инсульта в клиническую практику связано со значительным улучшением исходов в сочетании с рентабельностью [12].

Кроме того, важным аспектом в оказании медицинской помощи пациентам с ОНМК является вторичная профилактика заболевания, которая помимо лечебных мероприятий, включает в себя и повышение информированности пациентов о симптомах, факторах риска и других аспектов инсульта [13]. Внедрение образовательных программ для пациентов с инсультом продемонстрировало свою эффективность в различных странах, в Т.ч. и в РФ [14].

Цель исследования - оценить основные результаты работы сосудистых центров и отделений Тюменской области, а также образовательных мероприятий по вторичной профилактике инсульта за период 2011-2017гг.

\section{Материал и методы}

С целью обеспечения своевременной и качественной медицинской помощи пациентам с ОНМК в Тюменской области в 2011г были открыты региональный сосудистый центр (РСЦ) на 90 коек в ГБУЗ ТО “Областная клиническая больница № 2” (г. Тюмень) и первичные сосудистые отделения (ПСО) на 30 коек каждый на базе ГБУЗ ТО “Областная больница № 3" (г. Тобольск), ГБУЗ ТО “Областная больница № 4” (г. Ишим) и ГБУЗ ТО “Областная больница № 23” (г. Ялуторовск) (Приказ Департамента здравоохранения Тюменской области № $580 \mathrm{c}$ от 10 марта 2011г).

Деятельность этих отделений регламентирована следующим перечнем приказов РФ: Приказ МЗ и СР РФ № 389н от 06 июля 2009г “Об утверждении Порядка оказания медицинской помощи больным с острыми нарушениями мозгового кровообращения"; Приказ МЗ и СР РФ № 331 от 11 июля 2008г "О порядке организации мониторинга реализации мероприятий, направленных на совер- 
Таблица 1

Показатели деятельности РСЦ и ПСО Тюменской области в период 2011-2017гг

\begin{tabular}{|c|c|c|c|c|c|c|c|}
\hline \multirow[t]{2}{*}{ Показатели } & \multicolumn{7}{|c|}{ Годы } \\
\hline & 2011 & 2012 & 2013 & 2014 & 2015 & 2016 & 2017 \\
\hline $\begin{array}{l}\text { Число госпитализированных } \\
\text { пациентов с ОНМК } \\
\text { (G45; I60-I66.9), n }\end{array}$ & 2751 & 3374 & 3670 & 3888 & 4099 & 4256 & 4402 \\
\hline $\begin{array}{l}\text { Частота госпитализации больных } \\
\text { с ОНМК в первые } 24 \text { ч }\end{array}$ & $2141(77,8 \%)$ & $2455(72,8 \%)$ & $2549(69,5 \%)$ & $2926(75,3 \%)$ & $3059(74,6 \%)$ & $3175(74,6 \%)$ & $3358(76,3 \%)$ \\
\hline $\begin{array}{l}\text { Пациенты с ИИ, } \\
\text { госпитализированные в первые } 3 \text { ч }\end{array}$ & $142(7,8 \%)$ & $545(22,0 \%)$ & $516(19,0 \%)$ & $716(25,2 \%)$ & $626(20,6 \%)$ & $590(18,8 \%)$ & $633(20,0 \%)$ \\
\hline $\begin{array}{l}\text { Пациенты с ОНМК, } \\
\text { госпитализированные минуя } \\
\text { приемное отделение }\end{array}$ & $180(6,5 \%)$ & $2408(71,4 \%)$ & $3485(95,0 \%)$ & $3677(94,6 \%)$ & $3802(92,7 \%)$ & $4038(94,9 \%)$ & $3077(69,9 \%)$ \\
\hline $\begin{array}{l}\text { Пациенты, которым проведено } \\
\text { нейровизуализационное } \\
\text { исследование }\end{array}$ & $2596(94,4 \%)$ & $3371(99,9 \%)$ & $3330(90,7 \%)$ & $3720(95,7 \%)$ & $3733(91,1 \%)$ & $4178(98,2 \%)$ & $4402(100 \%)$ \\
\hline $\begin{array}{l}\text { Пациенты, которым проведено } \\
\text { нейровизуализационное } \\
\text { исследование в течение первых } \\
40 \text { мин от момента поступления }\end{array}$ & $1542(56,0 \%)$ & $3199(94,8 \%)$ & $3250(88,6 \%)$ & $3567(91,7 \%)$ & $3544(86,5 \%)$ & $3967(93,2 \%)$ & $4326(98,3 \%)$ \\
\hline $\begin{array}{l}\text { Частота выполнения системной ТЛТ } \\
\text { у больных с ИИ }\end{array}$ & $16(0,9 \%)$ & $32(1,3 \%)$ & $36(1,3 \%)$ & $61(2,1 \%)$ & $76(2,5 \%)$ & $141(4,5 \%)$ & $194(6,1 \%)$ \\
\hline $\begin{array}{l}\text { Пациенты с клиническим } \\
\text { улучшением после ТЛТ }\end{array}$ & $10(62,5 \%)$ & $20(62,5 \%)$ & $30(83,3 \%)$ & $46(75,4 \%)$ & $57(75,0 \%)$ & $105(74,5 \%)$ & $172(88,7 \%)$ \\
\hline $\begin{array}{l}\text { Пациенты с осложнениями после } \\
\text { ТЛТ, \% }\end{array}$ & $1(6,25 \%)$ & $3(9,4 \%)$ & - & $2(3,3 \%)$ & $2(2,6 \%)$ & $6(4,3 \%)$ & $6(3,1 \%)$ \\
\hline $\begin{array}{l}\text { Пациенты, независимые } \\
\text { в повседневной жизни к концу } \\
\text { стационарного лечения }\end{array}$ & $978(35,6 \%)$ & $1522(45,1 \%)$ & $1817(49,5 \%)$ & $1987(51,1 \%)$ & $2126(51,9 \%)$ & $2138(50,2 \%)$ & $2446(55,6 \%)$ \\
\hline Летальность от ОНМК & $383(13,9 \%)$ & $586(17,4 \%)$ & $605(16,5 \%)$ & $687(17,7 \%)$ & $677(16,5 \%)$ & $662(15,6 \%)$ & $634(14,4 \%)$ \\
\hline
\end{tabular}

шенствование оказания медицинской помощи больным с сосудистыми заболеваниями"; Приказ МЗ и СР РФ № 930 от 30 ноября 2009г “О внесении изменений в приказ МЗ и СР РФ от 11 июля 2008г № 331 “О порядке организации мониторинга реализации мероприятий, направленных на совершенствование оказания медицинской помощи больным с сосудистыми заболеваниями"; Приказ МЗ и СР РФ № 1044н от 30.12.2009г “Об утверждении Порядка оказания медицинской помощи больным с сердечно-сосудистыми заболеваниями, требующими диагностики или лечения с применением хирургических и/или рентгенэндоваскулярных методов"; Приказ М3 и СР РФ № 44н от 02 февраля 2010г “О внесении изменений в приказ МЗ и СР РФ от 06 июля 2009г № 389н "Об утверждении Порядка оказания медицинской помощи больным с острыми нарушениями мозгового кровообрашения"; Приказ МЗ и СР РФ № 357н от 27 апреля 2011г "О внесении изменений в приказ МЗ и СР РФ от 15 ноября 2012г № 928н “Об утверждении Порядка оказания медицинской помощи больным с острыми нарушениями мозгового кровообрашения".

Оснащение оборудованием к открытию РСЦ и ПСО было проведено в соответствии с приложением "Порядок оказания медицинской помощи больным с острыми нарушениями мозгового кровообращения". За шестилетний период госпитализировано 26440 пациентов с ОНМК.

Для оценки эффективности работы сосудистых центров и отделений анализировали следующие показатели число госпитализированных пациентов с ОНМК; частоту госпитализации больных с ОНМК в первые 24 ч; процент пациентов с ишемическим инсультом (ИИ), госпитализированных в первые 3 ч; процент пациентов с ОНМК, госпитализированных минуя приемное отделение; процент пациентов, которым проведено нейровизуализационное исследование, в т.ч. в течение первых 40 мин от момента поступления; частоту выполнения системной тромболитической терапии (ТЛТ) у больных с ИИ; процент пациентов с клиническим улучшением и осложнениями после ТЛТ; процент пациентов, независимых в повседневной жизни к концу стационарного лечения; летальность от ОНМК.

Кроме того, проанализированы результаты работы школ для пациентов с ОНМК и их родственников с помощью специально разработанной анкеты, которую респонденты заполняли после прохождения обучения в школах.

Статистическая обработка результатов исследования проводилась с использованием Microsoft Excel и SPSS 15.0 и Statistica 8.0 for Windows (StatSoftInc., USA). Эпидемиологические показатели рассчитывались как в абсолютных единицах измерения, простым суммированием числа заболевших больных, так и в относительных, в расчете на единицу численности населения. Различия считались статистически значимыми при уровне ошибки $\mathrm{p}<0,05$.

\section{Результаты}

За оцениваемый период выявлено увеличение числа пациентов, поступивших в первые 3 ч от 
Таблица 2

Летальность от ОНМК в РСЦ и ПСО Тюменской области в период 2011-2017гг

\begin{tabular}{lllllllll}
\hline & & 2011 & 2012 & 2013 & 2014 & 2015 & 2016 & 2017 \\
\hline \multirow{2}{*}{$\begin{array}{l}\text { ГИ } \\
4070)\end{array}$} & $\mathrm{n}$ & 451 & 545 & 571 & 649 & 576 & 605 & 673 \\
& Всего & $136(30,1 \%)$ & $217(39,8 \%)$ & $225(39,4 \%)$ & $281(43,3 \%)$ & $257(44,6 \%)$ & $271(44,8 \%)$ & $274(40,7 \%)$ \\
\cline { 2 - 8 } & В первые 24 ч & $15(3,3 \%)$ & $34(6,2 \%)$ & $41(7,2 \%)$ & $40(6,2 \%)$ & $26(4,5 \%)$ & $36(6,0 \%)$ & $32(4,8 \%)$ \\
\cline { 2 - 8 } & В первые 7 сут. & $73(16,2 \%)$ & $122(22,4 \%)$ & $138(24,2 \%)$ & $145(22,3 \%)$ & $139(24,1 \%)$ & $161(22,6 \%)$ & $97(14,4 \%)$ \\
\hline \multirow{2}{*}{$\begin{array}{l}\text { ИИ } \\
\text { 19267) }\end{array}$} & $\mathrm{n}$ & 1831 & 2477 & 2719 & 2846 & 3035 & 3142 & 3163 \\
& Всего & $247(13,5 \%)$ & $369(14,9 \%)$ & $380(14,0 \%)$ & $406(14,3 \%)$ & $420(13,8 \%)$ & $391(12,4 \%)$ & $360(11,4 \%)$ \\
\cline { 2 - 8 } & В первые 24 ч & $20(1,1 \%)$ & $19(0,8 \%)$ & $20(0,7 \%)$ & $33(1,2 \%)$ & $26(0,9 \%)$ & $15(0,5 \%)$ & $16(0,5 \%)$ \\
\cline { 2 - 8 } & В первые 7 сут. & $140(7,6 \%)$ & $188(7,6 \%)$ & $199(7,3 \%)$ & $184(6,5 \%)$ & $202(6,7 \%)$ & $173(5,5 \%)$ & $120(3,8 \%)$ \\
\cline { 2 - 8 } & После ТЛТ & $3(0,2 \%)$ & $9(0,4 \%)$ & $3(0,1 \%)$ & $6(0,2 \%)$ & $7(0,2 \%)$ & $9(0,3 \%)$ & $16(0,5 \%)$ \\
\hline
\end{tabular}

начала заболевания с 7,8\% в 2011г до 20,0\% в 2017г, что в 2,6 раза чаще $(\mathrm{p}<0,05)$. Госпитализация в срок $>24$ ч была на стабильном уровне, и была обусловлена как поздней обращаемостью пациентов и их родственников за медицинской помощью в связи с недостаточным распознавание симптомов инсульта и непониманием необходимости в неотложном оказании медицинской помощи, так и транспортировкой больных из центральных районных больниц санитарной авиацией.

Госпитализация больных с ОНМК, минуя приемное отделение, также стала проводиться значимо чаще: с 6,5\% в 2011г до 69,9\% в 2017г - в 10,8 раза чаще $(\mathrm{p}<0,05)$, что позволило сократить сроки обследования, при этом в период 2013-2016гг этот показатель был самым высоким - от 92,7\% до 95,0\%.

Нейровизуализационное исследование в течение первых 40 мин от момента поступления в РСЦ и ПСО выполнялось практически всем пациентам, начиная с 2012г.

Ежегодно наблюдалось увеличение числа пациентов, которым была выполнена ТЛТ с 0,9\% от общего количества ИИ в 2011г до 6,1\% в 2017г. Целевым показателем доли ТЛТ, проводимой при ИИ, является 5\%, таким образом, к 2017г РСЦ и ПСО Тюменской области достигли этих значений.

Одним из основных компонентов в организации РСЦ и ПСО является ранняя реабилитация, которая в значительной степени определяет исход лечения. Реабилитация пациентов с ОНМК подразумевает работу мультидисциплинарной команды, целью которой является оптимизация функциональных возможностей пациентов для обеспечения успешной реинтеграции в семью, социум, возвращения на работу. Хорошо организованные мультидисциплинарные реабилитационные команды обеспечивают снижение заболеваемости, смертности и зависимости пациентов от окружающих. По рекомендациям Всемирной организации здравоохранения среди выживших пациентов с ОНМК $70 \%$ должны быть полностью независимыми в повседневной жизни через 3 мес. после развития заболевания. В ПСО и РСЦ Тюменской области пациенты получают раннее реабилитационное лечение с первых сут. пребывания в течение всего периода пребывания в стационаре. Благодаря эффективному внедрению методов ранней реабилитации, доля пациентов, независимых в повседневной жизни к концу стационарного лечения (не $>2$-х баллов по шкале Рэнкин), в период 2011-2017гг увеличилась в 1,6 раза $(\mathrm{p}<0,05)$ и составила $55,6 \%$ в 2017г (таблица 1).

Летальность от ИИ в 2017г снизилась на 2,1\% по сравнению с 2011г, и составила 11,4\% (по РФ этот показатель составил 15,7-16,8\% в 2015-2016гг), тогда как летальность от геморрагического инсульта (ГИ) повысилась, составив 40,7\% (по РФ этот показатель составил 38,7\% в 2015 и 2016гг) (таблица 2).

Для оптимизации последующего наблюдения и лечения пациентов с ОНМК возникла необходимость повышения уровня самообразования пациентов и родственников или лиц, осуществляющих уход. Исследования демонстрируют низкую осведомленность общества о симптомах инсульта и факторах риска его возникновения.

В связи с этим в ПСО и РСЦ Тюменской области с 2012г для пациентов с ОНМК и их родственников во всех сосудистых центрах Тюменской области были организованы школы, направленные на повышение медицинской грамотности населения в отношении инсульта, целью которых явились:

- оптимизация, совершенствование, повышение доступности и качества медицинской профилактической помощи населению, в частности пациентам с ОНМК;

- повышение информированности пациентов с ОНМК о заболевании и факторах риска его развития;

- повышение ответственности за сохранение своего здоровья;

- формирование у пациентов рационального и активного отношения к заболеванию;

- формирование мотивации к оздоровлению, приверженности лечению и выполнений рекомендаций врача. 
Результаты анкетирования по проведенным школам для пациентов, перенесших инсульт, и их родственников в РСЦ и ПСО Тюменской области

\begin{tabular}{|c|c|c|c|c|}
\hline \multirow[t]{2}{*}{ Варианты ответов } & \multicolumn{2}{|c|}{ Пациенты } & \multicolumn{2}{|c|}{ Родственники } \\
\hline & $\begin{array}{l}\text { Мужчины } \\
(\mathrm{n}=560)\end{array}$ & $\begin{array}{l}\text { Женщины } \\
(\mathrm{n}=1040)\end{array}$ & $\begin{array}{l}\text { Мужчины } \\
(\mathrm{n}=168)\end{array}$ & $\begin{array}{l}\text { Женщины } \\
(\mathrm{n}=432)\end{array}$ \\
\hline \multicolumn{5}{|c|}{ Достаточна ли полученная Вами информация на занятии? } \\
\hline Да & $512(91,4 \%)$ & $969(93,2 \%)$ & $150(89,3 \%)$ & $385(89,1 \%)$ \\
\hline Нет & $8(1,5 \%)$ & $10(0,9 \%)$ & $4(2,4 \%)$ & $16(3,7 \%)$ \\
\hline Затрудняюсь ответить & $40(7,1 \%)$ & $61(5,9 \%)$ & $14(8,3 \%)$ & $31(7,2 \%)$ \\
\hline \multicolumn{5}{|c|}{ Доступно ли Вам была донесена информация? } \\
\hline Да & $551(98,4 \%)$ & $1014(97,5 \%)$ & $163(97,0 \%)$ & $412(95,4 \%)$ \\
\hline Нет & $1(0,1 \%)$ & $9(0,9 \%)$ & - & $6(1,4 \%)$ \\
\hline Затрудняюсь ответить & $8(1,5 \%)$ & $17(1,6 \%)$ & $5(3,0 \%)$ & $14(3,2 \%)$ \\
\hline \multicolumn{5}{|c|}{ Получили Вы практические навыки по уходу за больным? } \\
\hline Да & $484(86,4 \%)$ & $984(94,6 \%)$ & $139(82,7 \%)$ & $387(89,6 \%)$ \\
\hline Нет & $8(1,5 \%)$ & $11(1,1 \%)$ & $7(4,2 \%)$ & $8(1,8 \%)$ \\
\hline Затрудняюсь ответить & $68(12,1 \%)$ & $45(4,3 \%)$ & $22(13,1 \%)$ & $37(8,6 \%)$ \\
\hline \multicolumn{5}{|c|}{ Можете ли Вы оказать помощь человеку, у которого внезапно возник инсульт? } \\
\hline Да & $550(98,2 \%)$ & $1032(99,2 \%)$ & $166(98,8 \%)$ & $426(98,6 \%)$ \\
\hline Нет & - & $1(0,1 \%)$ & - & $1(0,2 \%)$ \\
\hline Затрудняюсь ответить & $10(1,8 \%)$ & $7(0,7 \%)$ & $2(1,2 \%)$ & $5(1,2 \%)$ \\
\hline \multicolumn{5}{|c|}{ Достаточно ли Вам раздаточного материала (буклеты, листовки, методические рекомендации)? } \\
\hline Да & $475(84,8 \%)$ & $952(91,5 \%)$ & $130(77,4 \%)$ & $366(84,7 \%)$ \\
\hline Нет & $45(8,0 \%)$ & $49(4,7 \%)$ & $17(10,1 \%)$ & $54(12,5 \%)$ \\
\hline Затрудняюсь ответить & $40(7,2 \%)$ & $39(3,8 \%)$ & $21(12,5 \%)$ & $12(2,8 \%)$ \\
\hline \multicolumn{5}{|c|}{ Удовлетворены Вы проведенной “Школой для пациентов, перенесших инсульт, и их родственников” } \\
\hline Да & $507(90,5 \%)$ & $990(95,2 \%)$ & $145(86,3 \%)$ & $387(89,6 \%)$ \\
\hline Нет & $11(2,0 \%)$ & $16(1,5 \%)$ & $8(4,8 \%)$ & $24(5,6 \%)$ \\
\hline Затрудняюсь ответить & $42(7,5 \%)$ & $34(3,3 \%)$ & $15(8,9 \%)$ & $21(4,8 \%)$ \\
\hline
\end{tabular}

Каждая школа курирует 10 следующих тем:

- артериальная гипертония и инсульт;

- ожирение как фактор риска инсульта. Здоровое питание;

- курение и здоровье;

- физическая активность и здоровье;

- стресс и здоровье;

- первичная профилактика сосудистых заболеваний;

- вторичная профилактика сосудистых заболеваний;

- позиционирование в реабилитации;

- место логопеда в обучении родственников, перенесших ОНМК (коммуникативные стратегии);

- жизнь после инсульта.

Групповые занятия проводят специально обученные врачи неврологи, кардиологи, эндокринологи, диетологи и медицинские сестры. Для закрепления информации слушателям выдают специально подготовленные памятки и брошюры.

Всего за период 2012-2017гг обучение в школах прошли 8254 человека, из которых 5243 (63,5\%) являлись пациентами сосудистых центров, перенесшими инсульт, и 3011 (36,5\%) - их родственники или лица, осуществляющие уход.
Для оценки эффективности проводимых мероприятий, а также получения обратной связи от слушателей, после завершения каждой из школ слушатели заполняли специально разработанную анкету. Были проанализированы 2200 анкет, из которых $1600(72,7 \%)$ заполнили пациенты и $600(27,3 \%)-$ родственники. Результаты проведенного анкетирования представлены в таблице 3 .

Абсолютно все респонденты дали утвердительный ответ на вопрос "Как Вы считаете, нужно ли проводить подобные школы для пациентов с инсультом и их родственников?”. 2016 (91,6\%) респондентов - $1481(92,6 \%)$ пациентов и $535(89,2 \%)$ родственников, сообщили, что получили достаточно информации на проводимых занятиях; 2140 $(97,3 \%)-1565(97,8 \%)$ пациентов и $575(95,8 \%)$ родственников, указали, что информация на занятиях была донесена доступно. Важным аспектом является получение практических навыков по уходу за пациентами и 1994 (90,6\%) человек: 1468 (91,8\%) пациентов и $526(87,7 \%)$ родственников, сообщили, что одним из результатов посещения школ стало получение знаний и навыков по уходу за пациентами с ОНМК. $2174(98,8 \%)$ респондента: 1582 $(98,9 \%)$ пациента и $592(98,7 \%)$ родственника, сооб- 
щили, что могут оказать помощь человеку, у которого внезапно возник инсульт. Большинство респондентов $(1923 ; 87,4 \%)$ указали, что им достаточно дополнительного материала, который раздавали на занятиях в школах и практически все (2029; 92,2\%) были удовлетворены проведенными образовательными мероприятиями.

\section{Заключение}

В последние годы на основании доказательной медицины были внесены существенные изменения в оказание помощи пациентам с ОНМК как в России, так и за рубежом. Лечение инсульта требует комплексного подхода, включая обеспечение маршрутизации, возможность раннего проведения диагностики и реабилитации, что позволяет существенно уменьшить последствия заболевания.

За шестилетний период работы РСЦ и ПСО в Тюменской области внедрены новые методы орга-

\section{Литература/References}

1. Roth GA, Johnson C, Abajobir A, et al. Global, regional, and national burden of cardiovascular diseases for 10 causes, 1990 to 2015. JACC. 2017;70(1):1-25. doi:10.1016/j.jacc.2017.04.052.

2. Feigin VL, Abajobir AA, Abate KH, et al. GBD 2015 Neurological Disorders Collaborator Group. Global, regional, and national burden of neurological disorders during 19902015: a systematic analysis for the Global Burden of Disease Study 2015. Lancet Neurol. 2015;16(11):877-97. doi:10.1016/S1474-4422(17)30299-5.

3. Stakhovskaia LV, Klochikhina OA, Bogatyreva MD, Kovalenko VV. Epidemiology of stroke in the Russian Federation: results of territory's population registry (20092010). Zhurnal nevrologii i psihiatrii im. C.C. Korsakova. 2013;113(5-1):4-10. (In Russ.) Стаховская Л.В., Клочихина О.А., Богатырева М.Д., К Коваленко В.В. Эпидемиология инсульта в России по результатам территориально-популяционного регистра (2009-2010). Журнал неврологии и психиатрии им. С. С. Корсакова. 2013;113(5-1):4-10.

4. Feigin VL, Krishnamurthi RV, Parmar P, et al; GBD 2013 Writing Group; GBD 2013 Stroke Panel Experts Group. Update on the global burden of ischemic and hemorrhagic stroke in 1990-2013: the GBD 2013 study. Neuroepidemiology. 2015;45(3):161-76. doi:10.1159/000441085.

5. Suslina ZA, Varakin JuJa. Clinical guidance on early diagnostics, treatment and prevention of cerebrovascular diseases. M.: MEDpress-inform 2015; 438 p. (In Russ.) Суслина 3.А., Варакин Ю.Я. Клиническое руководство по ранней диагностике, лечению и профилактике сосудистых заболеваний головного мозга. М.: МЕДпресс-информ 2015; 438 с. ISBN 978-5-00030-459-4.

6. Schwamm LH, Pancioli A, Acker JE 3rd, et al. American Stroke Association's Task Force on the Development of Stroke Systems. Recommendations for the establishment of stroke systems of care: recommendations from the American Stroke Association's Task Force on the Development of Stroke Systems. Stroke. 2005;36(3):690-703. doi:10.1161/01.cir.0000154252.62394.1e.

7. Stroke Unit Trialists' Collaboration. Organised inpatient (stroke unit) care for stroke. Cochrane Database Syst Rev. 2013;(9):Cd000197. doi:10.1002/14651858. CD000197.pub3. низации помощи больным инсультом, современные технологии диагностики и лечения, мультидисциплинарный подход к ранней нейрореабилитации, что позволило увеличить число выполнений системной ТЛТ, снизить показатели летальности у пациентов с ИИ и улучшить функциональные исходы.

Внедрение школ для пациентов с инсультом и их родственников существенно повысило информированность целевой группы населения об основных симптомах, факторах риска, а также методов первичной и вторичной профилактики инсульта.

Таким образом, с внедрением РСЦ и ПСО специализированная помощь больным с ОНМК в Тюменской области значительно улучшилась.

Конфликт интересов: авторы заявляют об отсутствии потенциального конфликта интересов, требующего раскрытия в данной статье.

Wardlaw JM, Murray V, Berge E, del Zoppo GJ. Thrombolysis for acute ischaemic stroke. Cochrane Database Syst Rev. 2014;(7):Cd000213. doi:10.1002/14651858. CD000213.pub3.

9. Badhiwala JH, Nassiri F, Alhazzani W, et al. Endovascular thrombectomy for acute ischemic stroke: a meta-analysis. JAMA. 2015;314(17):1832-43. doi:10.1001/ jama.2015.13767.

10. Pollock A, Baer G, Campbell P, et al. Physical rehabilitation approaches for the recovery of function and mobility following stroke. Cochrane Database Syst Rev. 2014;(4):Cd001920. doi:10.1002/14651858. CD001920.pub3.

11. Langhorne P, de Villiers L, Pandian JD. Applicability of stroke-unit care to low-income and middle-income countries. Lancet Neurol. 2012;11(4):341-8. doi:10.1016/s14744422(12)70024-8.

12. Zhai S, Gardiner F, Neeman T, et al. The cost-effectiveness of a stroke unit in providing enhanced patient outcomes in an Australian teaching hospital. J Stroke Cerebrovasc Dis. 2017;26(10):2362-8. doi:10.1016/j.jstrokecerebrovasdis.2017.05.025.

13. Baklushina EK, Bursikova DV, Nuzhenkova MV, et al. Health awareness of patients undergoing stroke and its condition and performance in the second phase rehabilitation. Kurortnaja medicina. 2016;2:98-101. (In Russ.) Баклушина E. K., Бурсикова Д. В., Нуженкова М. В. и др. Медицинская информированность пациентов, перенесших инсульт, ее состояние и динамика в условиях второго этапа реабилитации. Курортная медицина. 2016;2:98-101.

14. Parfenov VA, Verbickaja SV. Secondary prevention of ischemic stroke: international recommendations and clinical practice. Nevrologicheskij zhurnal. 2014;2:4-10. (In Russ.) Парфенов В.А., Вербицкая С.В. Вторичная профилактика ишемического инсульта: международные рекомендации и клиническая практика Неврологический журнал. 2014;2:4-10. doi:10.18821/1560-9545-2014-19-2-4-10. 